\title{
ATUAÇÃO DA INTELIGÊNCIA ARTIFICIAL NO PROCESSO DE INTERPRETAÇÃO: UMA VISÃO A PARTIR DA HERMENÊUTICA GADAMERIANA
}

\author{
PERFORMANCE OF ARTIFICIAL INTELLIGENCE \\ IN THE PROCESS OF INTERPRETATION: A VIEW \\ FROM GADAMERIAN HERMENEUTICS
}

\author{
Renata Albuquerque Lima \\ Marina Nogueira de Almeida
}

\section{RESUMO}

O presente trabalho busca fazer uma análise comparativa entre as "atividades neurais" do ser humano e de computadores dotados de Inteligência Artificial para posteriormente avaliar a presença ou não de aptidão interpretativa de um sistema sob a ótica de Gadamer. Conceitua-se e demonstra-se a evolução das novas tecnologias "inteligentes". Depois, analisa-se os principais aspectos da teoria hermenêutica gadameriana e, por fim, estuda-se os critérios mais importantes para o procedimento de interpretação. Para a elaboração deste artigo, foi utilizada uma pesquisa teórico-bibliográfica e documental, na qual se fez basilar o estudo de livros e artigos pertinentes aos assuntos tratados. A fundamental relevância desse trabalho é aprofundar os conhecimentos sobre a hermenêutica filosófica ontológica, ainda merecedora de bastante discussão.

Palavras-chave: Inteligência Artificial. Hermenêutica gadameriana. Interpretação. Máquina. Redes neurais.

\section{ABSTRACT}

The following work aims to comparatively analyze the "neural activities" of the human being and computers endowed with Artificial Intelligence to subsequently evaluate, from Gadamer's point of view, the presence or nonpresence of the interpretation aptitude of a system. The evolution of new 
"smart" technologies will be conceptualized and demonstrated. Afterwards, the main aspects of the hermeneutic theory of Gadamer will be analyzed and, finally, the most important criteria for the interpretation process will be studied. To elaborate this article, it was used a theoretical-bibliographical and documental research, and the study of books and relevant articles about the subjects mentioned above was fundamental. The main relevance of this work is to deepen the knowledge about ontological philosophical hermeneutics, a theme that still deserves to be widely discussed.

Keywords: Artificial Intelligenc. Hermeneutics of Gadamer. Interpretation. Machine. Neural networks.

\section{INTRODUÇÃO}

A inteligência artificial (IA) é sem dúvida um tema extremamente atual e complexo. Pode-se definir, em um primeiro momento, como a capacidade das máquinas de pensarem como seres humanos: aprender, perceber e decidir quais caminhos seguir diante de determinadas situações. Os economistas chamam essa recente "Era digital" de a quarta revolução industrial, marcada pela convergência de tecnologias digitais, físicas e biológicas.

Nos dias de hoje, a IA está espalhada por todos os lugares: no chão de fábrica; nos sistemas de atendimento de hospitais e bancos; nas redes sociais, no celular, no antivírus e até nos buscadores da internet; dentre outros. Muito tem se propagado, em notícias veiculadas por vários meios de comunicação, que a IA já consegue ter habilidades cognitivas humanas. Porém, não tem um entendimento uniforme sobre isso, pois ensinar os computadores a pensar não é algo tão simples.

A maioria dos exemplos de IA do momento apenas são sistemas que podem ser treinados para cumprir tarefas específicas ao processar grandes quantidades de dados e reconhecer seus padrões.

Pesquisas são feitas nas mais variadas áreas da ciência da computação com o propósito de se chegar cada vez mais perto de um futuro em que as plataformas digitais terão inteligência suficiente para aprender. Houve um enorme avanço através de estudos sobre o funcionamento do cérebro 
humano, principalmente no que se refere às interligações dos neurônios, aplicados aos sistemas computacionais.

0 presente artigo tem como objetivo fazer uma análise comparativa entre as "atividades neurais" do ser humano e de aparelhos tecnológicos dotados de IA para posteriormente avaliar a aptidão interpretativa deste último. Não se pretende esgotar o tema ou mesmo conceituar precisamente cada tecnologia ou teoria apresentadas.

Considerando-se este contexto, inicia-se com uma breve abordagem dos conceitos e da evolução da IA mostrando as pesquisas feitas sobre a capacidade dessa tecnologia de, efetivamente, pensar e raciocinar. Posteriormente, passa-se ao estudo da teoria hermenêutica Gadameriana, relatando alguns aspectos que para o autor eram relevantes e fundamentais no processo de interpretação. Por fim, através de critérios comparativos, entrar-se-á na finalidade específica do trabalho que é a de verificar se a IA consegue ou não interpretar conforme Gadamer.

0 artigo segue o método de pesquisa bibliográfica e tem como relevância a contribuição para o aprofundamento do estudo científico sobre hermenêutica ontológica (assunto ainda relativamente incipiente se comparado com outras abordagens filosóficas).

Desse modo, questiona-se: Como se constitui a Inteligência Artificial? Possui uma real inteligência comparável com a do ser humano? A IA detém aptidão interpretativa segundo os métodos hermenêuticos de Gadamer?

\section{A ANÁLISE Do FUNCIONAMENTO DAS MÁQUINAS DOTADAS DE INTELIGÊNCIA ARTIFICIAL NO DESEMPENHO DA ATIVIDADE COGNITIVA}

Inicialmente é relevante entender o que significa inteligência artificial (IA). Em resumo, a IA é um campo da ciência e da engenharia da computação que tenta reproduzir as habilidades da inteligência humana em máquinas. Tudo isso só foi possível através de estudos sobre o funcionamento do cérebro humano adicionado a uma ideia bem antiga de que a mente seria uma espécie de máquina. Não haveria tanta diferença 
entre o sistema natural e o artificial e, por isso, um aparelho eletrônico também poderia pensar ${ }^{1}$.

Para os pesquisadores da Inteligência Artificial a mente humana funciona como um computador, e por isso o estudo dos programas computacionais é a chave para se compreender alguma coisa acerca de nossas atividades mentais. Podemos construir programas que imitem nossa capacidade de raciocinar, de perceber o mundo e identificar objetos que estão à nossa volta, e até mesmo de falar e de compreender a nossa linguagem (TEIXEIRA, 1990, p.2)

Assim, para o nascimento da IA, várias disciplinas científicas foram estudadas em conjunto para, no final, influenciar sua formação. Dentre outras, as mais importantes foram neurociência, linguística, psicologia, filosofia e tudo mais sobre ciência cognitiva (NAKABAYASHI, 2009).

0 cérebro humano é formado por um grande número de neurônios que são interligados. Essa complexa rede neuronal opera no processamento e troca de informações, gerando conhecimento e aprendizado. Cada neurônio é ativado por outro através das conexões sinápticas.

No caso da inteligência artificial, houve muitos estudos e tentativas de recriar essa conexão de informações dos neurônios para os processadores das máquinas. Elas estão sendo projetadas para simular como a mente realiza determinada tarefa ou função ${ }^{2}$.

Depois que criaram as redes neurais artificiais, as unidades de processamento conseguiram se comunicar em valores numéricos (como se fosse um diálogo linguístico), adquirindo e armazenando um conhecimento próprio. Dessa forma, "a rede é implementada por componentes elétricos, ou simulada através de software que realizam operações através de um processo de aprendizagem utilizando uma maciça conexão de unidade de simples processamento" (FERNANDES; et al, 2018).

Existem projeções de que as capacidades da inteligência artificial irão ultrapassar as do cérebro humano em poucos anos. 0 futurista, Ray Kurzweil, defende a ideia da singularidade das máquinas, ou seja, momento de autonomia total (independência do ser humano). Prevê que a primeira máquina verdadeiramente inteligente será construída no final 
da década de 2020 e que a singularidade, propriamente dita, ocorrerá em 2045 (FORD, 2019, p. 312-313).

Porém, qual é a definição de inteligência? Existe propriamente uma que seja artificial?

Segundo o dicionário Aurélio, o conceito da palavra inteligência é tido como o conjunto de todas as faculdades intelectuais (memória, imaginação, juízo, raciocínio, abstração e concepção); compreensão fácil; habilidade. O significado de inteligência artificial é tido como "ramo da informática que estuda o desenvolvimento de sistemas computacionais com base no conhecimento sobre a inteligência humana" (INTELIGÊNCIA, 2018, Online).

De imediato consegue-se perceber que existe uma diferença teórica entre inteligência natural e artificial. Os humanos têm a aptidão de aprendizado, de tomada de decisão baseada no conhecimento e nas experiências, de concluir, dentre outros. Já a IA tenta dar à máquina toda essa habilidade, porém, para isso, será preciso passar por um grande desenvolvimento tecnológico, pois a sua evolução ainda está em um alto processo de acontecimento.

No começo, o que existia era o computador que apenas analisava dados de forma mecânica e sem "inteligência”. Ele implementava as rotinas de software com um "set" específico de instruções para completar uma tarefa em particular

Posteriormente, surgiu a máquina com a capacidade de "aprendizado" - a Machine Learning. Essa tecnologia usa algoritmos para coletar dados, aprender com eles, e então fazer uma determinação ou predição sobre alguma coisa no mundo. A máquina, então, "é 'treinada' usando uma quantidade grande de dados e algoritmos que dão a ela a habilidade de aprender como executar a tarefa (DATA SCIENCE BRIGADE, 2016, Online).

Foram desenvolvidos em duas categorias: aprendizado supervisionado e não-supervisionado. No primeiro, os seres humanos fornecem a entrada e a saída desejada, além dos comentários sobre a precisão das previsões durante o treinamento. "Uma vez que o treinamento está completo, o algoritmo aplicará o que foi aprendido". Na segunda categoria, os sistemas não precisam ser treinados com dados de resultados desejados, pois "usam uma abordagem iterativa, um aprendizado profundo para realizar 
análise de quantidades exponenciais de dados e obter conclusões" (SOFTWARE ONE, 2017, Online).

E por fim, está em desenvolvimento o deep learning ${ }^{3}$ que são computadores com redes neurais artificiais profundas que possuem habilidades de improvisação. Nessa última fase, é possível que um computador consiga superar o homem no que se refere às capacidades mentais.

Vale ressaltar que a técnica mais aplicada na IA, atualmente, é a machine learning não-supervisionada. Simula o processo de raciocínio humano, avalia possibilidades e chega a um entendimento que apresentam as melhores soluções para um determinado caso sem a interferência humana. (FERNANDES; et al, 2018).

A compreensão dessa evolução de capacidade da inteligência artificial é fundamental pra saber em que nível os computadores estavam quando foram analisados por estudiosos durante os anos. Já vem de muito tempo o embate filosófico sobre se as máquinas têm a aptidão "humana" de pensar, ou se elas possuem apenas a aptidão de manipular símbolos.

Um dos teóricos da Inteligência Artificial, Allan Turing (1950, apud PORTO, 2006), propôs um teste para provar que os computadores efetivamente pensavam. Ele achava que não havia nenhuma diferença entre a máquina e o homem e, portanto, deduziu que se o computador conseguisse jogar uma partida do que ele chamou de "jogo da imitação", então seria uma máquina pensante.

Já Searle (1980, apud PORTO, 2006), em contraposição, propôs um experimento para refutar o teste de Turing. Fez um experimento que ficou conhecido como o "argumento da sala chinesa".

Todavia, não é necessário saber no que consistiu cada um desses testes, mas apenas é importante saber a conclusão que Searle chegou: o computador tem apenas habilidades sintáticas, enquanto o ser humano possui habilidades sintáticas e semânticas.

No século XXI, na era da "machine learning" e "deep learning", a inteligência artificial usa algoritmos para funcionar. Eles são, simplesmente, uma estruturação de regras de execução de tarefas ou resoluções de problemas. No entanto, o historiador israelense Yuval Harari (2018, p. 41) admite que os humanos também se utilizam de algoritmos bioquímicos 
para pensar e tomar decisões. Ele explica que as escolhas das pessoas não resultam de um "livre-arbítrio", mas sim de "bilhões de neurônios que calculam probabilidades numa fração de segundo, assim a 'Intuição humana' nada mais é do que a capacidade de reconhecer padrões".

Contudo, e quanto a interpretação? Seria esse um diferencial humano? Com o intuito de encontrar alguma resposta para esses questionamentos, é interessante analisar uma notícia atual sobre um caso que aconteceu em uma Universidade americana.

Em 16 de janeiro de 2018, o site da CNET divulgou uma matéria escrita por Zoey Chong (2018, Online) que foi intitulada da seguinte maneira: "AI beats humans in Stanford reading comprehension test", traduzindo: o título dizia que a inteligência artificial conseguiu se sair melhor no teste de compreensão de leitura de Stanford que os seres humanos.

0 que aconteceu foi o seguinte: dois sistemas dotados de IA empataram em primeiro lugar no SQuAD (Stanford Question Answering Dataset) que é um conjunto de dados de compreensão de leitura, composto por perguntas sobre um conjunto de artigos da Wikipédia. A resposta a cada pergunta é um segmento correspondente ao próprio texto lido (CHONG, 2018, online).

0 interessante foi que esses programas "inteligentes" fizeram uma pontuação maior do que o de uma pessoa, ou seja, ultrapassou a atividade humana de compreensão de texto. Porém, isso que a máquina conseguiu fazer foi interpretar ou ela apenas identificou padrões, visto que a notícia diz que as respostas estavam expressas no próprio texto?

0 modelo de IA utilizado nesse procedimento foi o Machine Reading Comprehension (MRC) ou Compreensão de Leitura de Máquina (CLM), ou seja, "habilidade de uma inteligência artificial fazer uso do deep learning para ler e compreender textos, tendo ainda a aptidão para responder perguntas baseadas em algumas passagens presentes no conteúdo" (FRED, 2018, Online).

Esse modelo, por sua vez, pode utilizar três formas de sistemas: perguntas e respostas; extração de informações e mineração de argumentos.

Um sistema de perguntas e respostas pesquisa uma grande coleção de textos e encontra uma frase curta que responda com precisão à pergunta de um usuário. A extração de informações resume os detalhes essenciais particulares de um determinado documento. Por fim, a 
mineração de argumentos envolve a identificação automática de estruturas argumentativas em textos de documentos, por exemplo, premissas e conclusão, e relações entre partes de argumentos (ASHLEY, 2017, p. 4-5).

O sistema aplicado na experiência de Standford foi o Question Answering - QA (perguntas e respostas). Na prática, o programa processa dados sequenciais e atribui "peso" às palavras mais relevantes dentro de um determinado contexto (FRED, 2018, Online).

Isso é atividade interpretativa? Quando a reportagem fala que o sistema "bateu" os humanos em um teste de compreensão de leitura, estaria apenas usando uma figura de linguagem, ou seja, uma espécie de metáfora?

Essas metáforas de personificação, entretanto, são polêmicas, porque, se por um lado há quem defenda que as máquinas não possuem uma verdadeira inteligência, os defensores da IA afirmam que elas podem sim pensar como um ser humano e, nesse caso, a proposição "meu computador pensa" estaria sendo tomada em seu sentido literal (PEREIRA; MOURA, 2008).

Ana Carolina Nunes (2018, p. 53-54), em sua dissertação sobre redes neurais naturais e artificiais, acrescenta o que seria experiência para um computador:

[...] as redes neurais artificiais são provenientes do deep learning (aprendizagem profunda) e buscam promover conexões semelhantes ao que os cientistas definem como sendo as conexões dos nossos cérebros, por meio dela, é como se um computador aprendesse com a experiência. Mas qual experiência? Tendo em vista que ele não é humano como nós? Bem, a experiência emulada pelo computador é composta por tudo o que é relativo ao assunto que ele busca desenvolver e que esteja disponível na internet, em diversos bancos de dados. Apesar de tudo isso, alguns/as cientistas são céticos em relação as redes neurais artificiais, especificamente porque ela necessita passar por um treinamento para passar a reconhecer algo, por exemplo, para uma máquina passar a reconhecer a imagem de um cachorro automaticamente, ela terá que visualizar e analisar milhares de imagens de cachorros. 0 que é diferente do que acontece quando uma criança está aprendendo alguma coisa. Pois ela não precisa ver e analisar a mesma coisa milhares de vezes para que passe a reconhecê-la. No fim das contas, o cérebro humano é um grande enigma até mesmo para os cientistas. 
Verifica-se, assim, que muito ainda é discutido sobre o que o computador consegue ou não fazer. Nesse artigo, a proposta é analisar a capacidade interpretativa da máquina segundo os critérios hermenêuticos de Gadamer. Necessário entender, então, o que este autor explica na sua teoria hermenêutica.

\section{A HERMENÊUTICA GADAMERIANA: O FUNCIONAMENTO DA INTERPRETAÇÃO E SEUS REQUISITOS IMPRESCINDÍVEIS}

Hans-Georg Gadamer foi um prestigiado filósofo alemão que viveu do ano de 1900 até 2002. Dedicou-se ao estudo da hermenêutica filosófica e foi profundamente influenciado por Martin Heidegger ${ }^{4}$. Teve como obra de maior impacto o livro "Verdade e Método", na qual trata de vários assuntos como: interpretação, compreensão, linguagem, tradição, experiências, fusão de horizontes, dentre outros critérios relevantes para a hermenêutica.

Gadamer (2004) sustenta que é relevante saber onde o interprete está inserido, pois isso vai influenciar diretamente na forma de compreensão dele. Compreender e interpretar dependem da experiência do homem no mundo, que é o lugar onde as pessoas lidam com as coisas.

Para o autor, a estrutura temporal e histórica de quem irá interpretar é fundamental porque a vida é sempre envolta por um passado carregado de significação e, ao mesmo tempo, aponta para as projeções que podemos fazer em relação ao futuro (MISSAGGIA, 2012). "Os seres humanos são ocasionalmente caracterizados por Gadamer como estando sob a tutela da história" (KUSCH, 2001, p. 256).

Toda essa parte de inserção do homem no mundo, Gadamer chama de "história efeitual", ou seja, não temos controle total sobre a tradição, de maneira que somos determinados, em grande parte, por ela. Em uma relação entre o conhecedor e o conhecido, o sujeito (como ente histórico que é) parte sempre de uma vinculação direta com a tradição ao qual pertence (MISSAGGIA, 2012). 
Com relação a teoria da "fusão de horizontes", o autor demonstra que existe uma real agregação entre o horizonte do intérprete com o do texto. Ocorre que essa perspectiva do agente hermenêutico nunca é estabelecida por ele. "Os interpretes dependem da tradição, porque todos os seus interesses com relação a certas questões e respostas a determinado texto são pré-delineadas pela história efeitual” (KUSCH, 2001, p. 257). Ou seja, "implica em um encontro entre a tradição do intérprete e a do texto, entre o horizonte daquele que compreende e o horizonte que se reflete na própria obra" (RIBEIRO; BRAGA, 2008, p. 275).

Um conceito de Heidegger que influencia diretamente Gadamer é o de "círculo hermenêutico". Esse círculo "ocorre no instante em que o sujeito, através de sua pré-compreensão, participa na construção do sentido do objeto (moldado por tais preconceitos), a passo que o próprio objeto, no desenrolar do processo hermenêutico, modifica a compreensão do intérprete" (PEREIRA, 2001, p. 35).

A teoria gadameriana se preocupa, exatamente, em explicar como se escapa de um círculo fechado de opiniões preconcebidas. "A proposta é manter um constante interpretar até que os conceitos prévios deixem de sê-los, e ao longo da comunicação, sejam substituídos por outros conceitos novos mais adequados" (BONFIM, 2010, p. 77).

A experiência de vida e o diálogo ajudarão bastante o intérprete nesse processo de amadurecimento e mudança de pré-compreensão, ajudando-o, inclusive, na sua aproximação da verdade. Um universo verdadeiramente hermenêutico se forma pelo modo como se experimenta uns aos outros, as tradições históricas, as ocorrências naturais de existência e de mundo (GADAMER, 2004).

O próprio significado de experiência indica que a vida humana é finita. Demonstra que o homem conhece seus limites e sabe que não é o senhor do tempo nem do futuro. A consciência hermenêutica tem sua consumação na experiência, pois ela distingue o homem experimentado daquele que está preso aos dogmas (GADAMER, 2004).

Portanto, Gadamer deixa claro que "o intérprete não consegue alcançar suficientemente o ideal de deixar de lado a si mesmo" (GADAMER, 2004, p. 513). Seria impossível evitar que os seus próprios conceitos não o influenciassem no momento da leitura do texto, por exemplo. 
Outro ponto importante a ser analisado é sobre a existência da verdade. Para o autor, ela não se esgota através do uso de algum método. Pela noção de horizonte histórico, chega-se à conclusão de uma pluralidade de camadas de sentido, ou seja, uma constante mobilidade de significados cambiantes em função de cada época. Assim, não teria como se chegar a uma noção sobre a verdadeira realidade de algo (GADAMER, 2004).

É claro que o fato de não se ter uma verdade absoluta, pois a interpretação depende da experiência de mundo e horizonte histórico do intérprete, não significa que o autor admite uma interpretação ilimitada e sem critérios. Gadamer (2004) defende que não se pode isolar o homem do objeto. Isso quer dizer que o próprio texto, por exemplo, irá dizer até onde a interpretação poderá ir para ser válida, senão seria um disparate.

Fernando Ribeiro e Bárbara Braga (2008, p. 273), quando escreveram sobre Gadamer, apontaram a ideia dele sobre o assunto que é a seguinte:

A tarefa de descoberta da verdade do objeto é no todo impotente, pois o homem, ao debruçar-se sobre um objeto, não encontra apenas objeto, mas também ação humana refletida. Assim, a interpretação deixa de ser um processo reprodutivo para figurar como processo produtivo, posto que o intérprete não realiza apenas uma atividade reprodutiva do texto, mas o atualiza de acordo com as circunstâncias do momento. Ao projetar seu horizonte histórico, o intérprete dá origem a um novo horizonte no presente. 0 presente vem a ser como uma evolução do limitado horizonte histórico para um novo horizonte superador, numa fusão de horizontes.

Outro elemento essencial para a hermenêutica é a linguagem, pois através do entendimento dos fundamentos linguísticos é que se tem uma pré-direção para a interpretação. "A linguagem é o meio em que se realizam o acordo dos interlocutores e o entendimento sobre a coisa em questão" (GADAMER, 2004, p. 497). Assim ela também acaba limitando a experiência hermenêutica como um todo. Sabendo que tudo o que se quer entender a linguagem remete para além do enunciado, detecta-se que jamais será possível haver uma compreensão total de algo.

O caráter da linguagem da conversação [...] nos ensinou que, em última instância, compreender e interpretar são uma e a mesma coisa. [...] foi só através desse conhecimento que o conceito de interpretação se desvinculou 
da significação pedagógico-ocasional que recebeu no século XVIII, alcançando um lugar sistemático, que se caracteriza por representar o ponto-chave que o problema da linguagem alcançou para o questionamento filosófico (GADAMER, 2004, p. 503).

Por fim, originalmente, a hermenêutica tem como tarefa principal a compreensão dos textos e, para Gadamer, a forma de realização da compreensão é através da interpretação.

A interpretação é inserida num contexto em que interpretar permite ser compreendido progressivamente como uma autocompreensão de quem interpreta. Reconhecer o passado é fundamental para a compreensão e formação do conhecimento.

Juliana Missaggia (2012, p. 5) coloca no seu artigo uma referência ao pensamento de Gadamer em que ele diz:

[...] ao procurar compreender algo que lemos, sempre realizamos um "projetar" em relação ao sentido do todo, do mesmo modo que partimos das nossas concepções prévias que determinam a compreensão. É somente no confronto com o próprio texto que podemos chegar a questionar esse projetar e os prejuízos que guiaram a leitura. Mas o fato é que uma compreensão prévia do próprio texto já é dada de antemão antes de nossa leitura. Uma estrutura circular análoga estaria presente em qualquer atividade de compreensão.

Acrescentando, ainda, sobre o assunto da compreensão, vale ressaltar que "conceitos normativos como a opinião do autor ou a compreensão do leitor originário representam, na realidade, apenas um lugar vazio que se preenche de compreensão, de ocasião para ocasião" (GADAMER, 2004, p. 512).

Portanto, para Gadamer vários fatores são relevantes para que se tenha uma efetiva interpretação: consciência do mundo onde se vive; experiências; uma história de vida; tradições; horizontes hermenêuticos; compreensão; dentre outros.

A partir de tudo o que já foi apresentado, têm-se elementos suficientes para começar a fazer uma relação entre interpretação, na perspectiva de Gadamer, e o modo de funcionamento de uma máquina com inteligência artificial. 


\section{A MÁQUINA DOTADA DE INTELIGENCIA ARTIFICIAL POSSUI CAPACIDADE COGNITIVA-INTERPRETATIVA A PARTIR DOS CONCEITOS HERMENÊUTICOS DE GADAMER?}

Com a finalidade de esquematizar melhor a análise sobre se um computador com inteligência artificial pode sozinho, efetivamente, interpretar de acordo com a teoria hermenêutica de Gadamer, essa parte do artigo será dividida por critérios de avaliação.

\section{HERMENÊUTICA ONTOLÓGICA: COMPREENSÃO E INTERPRETAÇÃO}

Antes de tudo, é preciso entender que as teorias que o professor HansGeorg Gadamer desenvolveu têm como base a Hermenêutica filosófica e ontológica de Martin Heidegger. Ao tratar do problema ontológico, Heidegger voltou-se para o método fenomenológico de Edmund Husserl e empreendeu um estudo sobre a presença quotidiana do homem no mundo (PALMER, 1986).

Assim, a análise de Heidegger indicou que a "compreensão" e a "interpretação" são modos fundantes da existência humana (ontologia da compreensão). Nesse contexto, a hermenêutica não se refere apenas à ciência ou às regras de interpretação textual, mas, antes de qualquer coisa, explica o fenômeno da própria existência humana (PALMER, 1986).

No caso da máquina, Guattari (apud OLIVEIRA, 2005) entende que ela tenta substituir a linguagem do homem não para enfatizar o que o sujeito é, mas sublinhando apenas o que ele faz. Ou seja, no momento em que o computador não vai buscar a essência do ser humano (ou de si próprio) e, somente, repete as atividades que as pessoas fazem (imitação de ações), pode-se dizer, desta forma, que a esfera da ontologia clássica é repudiada.

Portanto, Gadamer, como estudioso da ontologia ${ }^{5}$, não defenderia que algo que não fosse baseado no "Dasein"6 (ser-aí) pertencesse a sua teoria hermenêutica. Para ele, a própria compreensão é um tema epistemológico e ontológico. Nesse contexto, como a noção de máquina 
repudia a esfera da ontologia heideggeriana (privilegia o "Ser"), observase, já nesse critério, a dificuldade de se considerar, segundo Gadamer, a possibilidade de a Inteligência Artificial interpretar.

\section{SUBJETIVIDADE E EXPERIÊNCIA DE VIDA}

Passando para a análise do aspecto da subjetividade, nota-se que seu conceito não é pacificado, ou seja, até a forma de enxergar essa expressão mostra-se subjetiva.

Alguns pesquisadores, como Garcia-roza (1988, apud MANGUEIRA, 2001), relacionam a subjetividade com a consciência humana e suas derivações. Constituir-se-ia através das seguintes instâncias: eu, pessoa, cidadão, sujeito. Seria sede da razão e do pensamento e também capacidade de identidade consigo mesmo, sujeito de direitos, virtude e verdade.

Assim, criam-se duas esferas autônomas e interativas: "um sujeito a um só tempo pensante e autobiografável (que conhece o mundo) e um objeto dado a priori que espera ser desvelado em sua intimidade pelo primeiro" (MANGUEIRA, 2001, p. 411).

Já outros, como Deleuze e David Hume, entendem que "subjetividade não é mais do que uma coleção de dados sem ordem, sem estrutura e sem lei, e não coincide com o sujeito porque este é apenas um efeito das articulações às quais as ideias estão submetidas" (MANGUEIRA, 2001, p. 413).

Nesse segundo ponto de vista, não seria possível falar em uma subjetividade geral, pois é na repetição da experiência que se constrói a subjetividade e a consciência. "O sujeito é persistência no tempo de um conjunto de afirmações e crenças decorrentes dos hábitos" que o qualificam e lhe conferem uma identidade provisória, que será "passível de mudança tão logo mudem as experiências que conformam seus hábitos" (MANGUEIRA, 2001, p. 413-414).

Dentre as duas óticas, seja qual for o sentido real de subjetividade, não se pode conceber que algo parecido possa ser implementado em um sistema tecnológico, visto que a IA não possui consciência de mundo nem da sua própria existência. 


\section{LINGUAGEM E DIÁLOGO}

Em 2016, foi publicado na revista Super Interessante que pesquisadores da divisão de inteligência artificial do Google criaram três softwares-robôs (Alice, Bob e Eve) que tinham a seguinte missão: "Alice deveria mandar uma mensagem criptografada para Bob, que deveria ser capaz de decodificá-la - driblando a espionagem de Eve, cujo objetivo era interceptar e ler a mensagem" (GARATTONI, 2016, Online). 0 detalhe foi que nenhum dos computadores foi ensinado previamente a fazer nada disso.

Usando somente as técnicas de rede neural, Alice e Bob conseguiram desenvolver seu próprio método de criptografia, comunicando-se sem que Eve decodificasse as informações. "Pela primeira vez na história, duas entidades de inteligência artificial conseguiram criar, sozinhas, um meio para se comunicar de forma secreta" (GARATTONI, 2016, Online).

Apesar do caso relatado ser algo realmente impressionante, sabese que tanto a forma de linguagem como a de diálogo operada pelas máquinas são bem distintas das que os seres humanos utilizam. Apesar de já existirem alguns esforços para ensinar linguística ao computador ${ }^{7}$, é certo que atualmente um aparelho eletrônico usa o sistema binário ${ }^{8}$ (composto por zeros e uns) como base da sua comunicação.

Carlos Bento da Silva (2006, p. 105), ao estudar sobre a tentativa de aplicação da linguística ao computador - Processamento Automático de Línguas Naturais (PLN) ${ }^{9}$, explica que ainda há uma grande distância, nesse ponto, entre a máquina e o homem:

Essa constatação, por um lado, evidencia a escassez, senão a falta, de modelos linguísticos computacionalmente implementáveis, o que tem deixado aos informatas a tarefa de, às duras penas, construírem seus "léxicos", "gramáticas", "analisadores gramaticais" e "planejadores de discurso"; por outro, revela o incômodo distanciamento que se estabelece entre o estudo do PLN e o estudo da linguagem humana, sobretudo porque este não reconhece no âmbito daquele um espaço de investigação legítimo para a compreensão dos fenômenos linguísticos.

Por fim, no caso do diálogo entre aparelhos, pode-se dizer que a analogia mais próxima seria a "Internet da Coisas"10. Basicamente, é a 
interligação de objetos com o objetivo de coleta e transferência de dados e informações. Porém, mesmo aqui, não se tem propriamente um diálogo, pois não há uma troca de ideias e de experiências nem o encontro de dois seres distintos em busca de transformação pessoal, visto que as coisas interligadas são consideradas uma única "entidade" apenas com extensões de saída diferentes.

A hermenêutica de Gadamer mergulha nos problemas puramente filosóficos da relação da linguagem com o Ser, com a compreensão, com a história, com a existência e com a realidade (PALMER, 1986). Portanto, após a análise desses critérios, não se verifica, até este momento, como a IA poderia interpretar sob a lógica Gadameriana.

\section{INTELIGÊNCIA}

Por fim, o critério da inteligência, como já foi dito no primeiro tópico, é discutível porque existem aqueles que defendem que computadores com IA conseguem efetivamente pensar. Porém, Stephen Hawking (2014, Online) se manifestou dizendo que a criação de uma máquina verdadeiramente pensante "seria o maior evento da história humana", logo ainda não existe.

"Nem mesmo o Watson da IBM, talvez a demonstração de inteligência artificial mais impressionante até o momento, chega ao menos perto de alguma coisa que possa ser razoavelmente comparada com a inteligência humana comum" (FORD, 2019, p. 308). Na realidade, toda tecnologia de inteligência artificial que existe hoje é IA limitada (Narrow $A)^{11}$.

Segundo Martin Ford (2019), o tipo de inteligência almejada pelos cientistas da tecnologia é a IA genérica ou geral (IAG) ${ }^{12}$. Seria uma máquina capacidade cognitiva comparável à humana, no sentido de que conseguiria cumprir tarefas genéricas sem precisar de uma programação específica. Um computador equipado com IAG compreenderia a linguagem em um nível muito fundamental e suas habilidades ingressariam em campos da elaboração inteligente e do conhecimento humanos de forma, até então, inimaginável. 
A IAG ainda é um objetivo um pouco distante ${ }^{13}$, pois está intimamente ligada ao estudo do cérebro humano e seu funcionamento, campo de pesquisa em que há muito a ser explorado, apesar dos avanços serem inegáveis.

Dessa maneira, Neil Wilkins (2019) afirma que a busca por um sistema inteligente capaz de conceber novas ideias, demonstrar que tem conhecimento de sua própria existência e conduzir conversas coerentes continua sendo o Santo Graal da pesquisa computacional. Contudo, enquanto os computadores não se igualam (ou até excedem) à capacidade humana de pensar, não se pode afirmar que uma máquina pode exercer atividade cognitiva, dentre elas a interpretação.

\section{CONSIDERAÇÕES FINAIS}

Ante o exposto, verifica-se que apesar dos anúncios, das notícias ou de alguns trabalhos jornalísticos veicularem a informação de que um sistema, ou qualquer computador que possua Inteligência Artificial, possa interpretar, ou que pensa e tem consciência, está apenas usando o recurso linguístico da metáfora, pois foi visto a incapacidade tecnológica disso.

0 artigo, especificamente, se propôs a analisar a possiblidade da IA conseguir interpretar de acordo com a teoria hermenêutica de Gadamer. Passou-se por vários critérios considerados essenciais por este autor para a atividade interpretativa, tais como: compreensão, experiência, linguagem e diálogo. Concluiu-se pela incompatibilidade desses conceitos com o que uma máquina consegue fazer atualmente.

A IA ainda não adquiriu efetivamente uma inteligência humana capaz de interpretar, pois trabalha apenas com atividades limitadas de processamento de dados e reconhecimento de padrões. Contudo, mesmo que um dia se chegue a uma máquina realmente inteligente, não seria admitido por Gadamer que essas atividades fossem classificadas como parte da hermenêutica ontológica, pois somente o ser humano possui consciência, sentimentos, experiências, desenvolvimento da linguagem e argumentação abstrata. 


\section{NOTAS}

1 O pensamento seria um tipo de computação e a lógica básica de cada um dos módulos da mente seria determinada pela programação genética de cada ser (PINKER, 2018).

2 Redes Neurais Artificias são inspiradas pelo entendimento da biologia sobre o cérebro humano -todas as interconexões entre neurônios. "Mas, diferente de um cérebro biológico onde qualquer neurônio pode se conectar com qualquer outro neurônio dentro de uma certa distância física, as redes neurais artificiais têm camadas discretas, conexões e direções de propagação de dados" (DATA SCIENCE BRIGADE, 2016, Online).

3 Andrew Ng colocou a palavra "deep" no deep learning, que descreve todas as camadas das redes neurais artificiais que foram aprofundadas. Atualmente, o reconhecimento de imagens por máquinas treinadas através de deep learning em alguns cenários possuem uma taxa de acerto maior que a de humanos, podendo identificar até indicadores de câncer no sangue e tumores em exames de ressonância magnética com mais facilidade (DATA SCIENCE BRIGADE, 2016, Online).

4 “Martin Heidegger (1889-1976) foi um filósofo alemão cuja obra talvez seja mais prontamente associada à fenomenologia e ao existencialismo [...]. Suas ideias exerceram uma influência seminal no desenvolvimento da filosofia europeia contemporânea" (WHEELER, 2018, Online).

5 Ontologia no heideggerianismo é a reflexão a respeito do sentido abrangente do ser, como aquilo que torna possível as múltiplas existências. Opõe-se à tradição metafísica que, em sua orientação teológica, teria transformado o ser em geral num mero ente com atributos divinos.

6 'O termo 'Dasein' serviu para designar a manifestação do ser enquanto ente. O Dasein se compreende a si mesmo enquanto ser que existe" (ROBERTO, 2009, Online).

7 Sobre esse assunto vide artigo "O estudo Lingüístico-Computacional da Linguagem" de Carlos Bento Dias da Silva (2006) que trata sobre o estudo do Processamento Automático de Línguas Naturais (PLN).

8 “[...] a única linguagem decifrável pelo computador: a linguagem de máquina que, em última instância, representa toda a informação manipulada pelo sistema computacional em termos de estruturas representadas exclusivamente por cadeias de 'zeros e uns'” (DA SILVA, 2006).

9 Esse processamento utiliza as técnicas de machine learning para encontrar padrões em grandes conjuntos de dados puros e reconhecer a linguagem natural (DA SILVA, 2006).

10 É a "ideia de uma rede mundial de objetos conectados que trocam informação entre si" (SINGER, 2012).

11 Tecnologias que são capazes de executar tarefas específicas tão bem quanto os homens, mas que não exibem faceta alguma da inteligência humana.

12 Aqui as máquinas finalmente possuiriam as mesmas características da inteligência humana.

13 "James Barrat pediu aos cientistas de computação que fizessem uma escolha entre quatro diferentes previsões de quando a Inteligência Artificial Genérica (IAG) seria alcançada. Os resultados foram os seguintes: $42 \%$ acreditavam que uma máquina pensante estaria entre nós já em 2030; $25 \%$ disseram que isso aconteceria por volta de 2050 e $20 \%$ afirmaram que isso só ocorreria em 2100. Apenas 2\% acreditavam que isso nunca iria acontecer" (FORD, 2019, p. 309). 


\section{REFERÊNCIAS}

ASHLEY, Kevin D. Artificial intelligence and legal analytics: new tools for law practice in the digital age. Cambridge University Press, 2017.

BONFIM, Vinícius Silva. Gadamer e a experiência hermenêutica. Revista CEJ, v. 14, n. 49, p. 76-82, 2010.

CHONG, Zoey. IA bate seres humanos no teste de compreensão de leitura de Stanford. Site da CNET, 16 de jan. 2018. Disponível em: <https://www.cnet. com/news/new-results-show-ai-is-as-good-as-reading-comprehension-as-weare/>. Acesso em: 10 jun. 2019.

DA SILVA, Carlos Bento Dias. O estudo lingüístico-computacional da linguagem. Letras de Hoje, v. 41, n. 2, p. 103-138, 2006.

DATA SCIENCE BRIGADE. A Diferença Entre Inteligência Artificial, Machine Learning e Deep Learning. 25 de ago. 2016. Disponível em: <https://medium. com/data-science-brigade/a-diferen\%C3\%A7a-entre-intelig\%C3\%AAnciaartificial-machine-learning-e-deep-learning-930b5cc2aa42>. Acesso em: 11 de jun. 2019.

FERNANDES, Janderson Gabriel Limeira et al. Inteligência Artificial: Uma Visão Geral. Revista Eletrônica Engenharia Estudos e Debates, v. 1, 2018.

FORD, Martin. Os Robôs e o futuro do emprego. Tradução de Claudia Gerpe Duarte. Rio de Janeiro: Best Business, 2019.

FRED, Luís. Machine Reading Comprehension - inteligência artificial que consegue ler e interpretar textos. Luisfredgs, 5 de ago. 2018. Disponível em: <https://medium.com/luisfredgs/uma-intelig\%C3\%AAncia-artificial-queconsegue-ler-e-interpretar-textos-da108a2f1041>. Acesso em: 12 de jun. 2019.

GADAMER, Hans-Georg. Verdade e Método. Tradução de Flávio Paulo Meurer. 6ª edição. Rio de Janeiro: Vozes, 2004.

GARATTONI, Bruno. Robôs do Google aprendem a se comunicar secretamente- entre si. Super Interessante, 21 dez 2016. Disponível em: $<$ https://super.abril.com.br/blog/bruno-garattoni/robos-do-google-aprendema-se-comunicar-secretamente-entre-si/>. Acesso em: 11 jun. 2019. 
INTELIGÊNCIA. Dicionário online Aurélio, 19 abr. 2018. Disponível em: <https://dicionariodoaurelio.com/inteligencia>. Acesso em: 10 jun. 2019.

HARARI, Yuval Noah. 21 lições para o século 21. Tradução de Paulo Geiger. São Paulo: Companhia das Letras, 2018.

HAWKING, Stephen, et al. Stephen Hawking: "A transcendência olha para as implicações da inteligência artificial - mas estamos levando a IA a sério o suficiente?" Independent, 1 mai. 2014. Disponível em: <https://www. independent.co.uk/news/science/stephen-hawking-transcendence-looks-atthe-implications-of-artificial-intelligence-but-are-we-taking-9313474.html>. Acesso em: 14 jun. 2019.

KUSCH, Martin. Linguagem como cálculo versus linguagem como meio universal: um estudo sobre Husserl, Heidegger e Gadamer. São Leopoldo: Unisinos, 2001.

MISSAGGIA, Juliana. A hermenêutica em Heidegger e Gadamer: algumas confluências e divergências. Griot: Revista de Filosofia, v. 6, n. 2, p. 1-13, 2012.

NAKABAYASHI, Luciana A. A contribuição da inteligência artificial (IA) na filosofia da mente. Dissertação. PUC-SP, São Paulo, 2009.

NUNES, Ana Carolina de Assis. Entres redes neurais naturais e artificiais: estudo antropológico sobre humanidade e inteligência artificial em algumas revistas brasileiras. Universidade Federal de Goiás. Goiânia, 2018.

OLIVEIRA, Rosana Medeiros De. Tecnologia e subjetivação: a questão da agência. Psicologia \& Sociedade, v. 17, n. 1, p. 17-28, 2005.

PALMER, Richard E. Hermenêutica. Tradução de Maria Luísa Ribeiro Ferreira. Lisboa: Edições 70, 1986.

PEREIRA, Ivelã; MOURA, Heronides Melo. Máquinas e mentes: interpretando a metáfora. Working Papers em Linguística, v. 9, n. 1, p. 81-99, 2008.

PINKER, Steven. Como a mente funciona. Editora Companhia das Letras, 2018.

PORTO, Leonardo Sartori. Uma investigação filosófica sobre a Inteligência Artificial. Informática na educação: teoria e prática. Porto Alegre. v. 9, n. 1 (jan./jun. 2006), p. 11-26, 2006. 
RIBEIRO, Fernando José Armando; BRAGA, Bárbara Gonçalves de Araújo. A aplicação do direito na perspectiva, hermenêutica de Hans-Georg Gadamer. Revista de Informação Legislativa. Brasília a. 45 n. 177, jan./mar. 2008.

ROBERTO, Luciano da Silva. Os modos de ser do "Dasein" a partir da analítica existencial heideggeriana. Pensamento Extemporâneo: Filosofia a qualquer tempo, 15 de ago. 2009. Disponível em: <http://pensamentoextemporaneo. com.br/?p=489>. Acesso em: 12 de jun. 2019.

SINGER, Talita. Tudo conectado: conceitos e representações da internet das coisas. Simpósio em tecnologias digitais e sociabilidade, v. 2, p. 1-15, 2012.

SOFTWARE ONE. Machine learning: como as máquinas aprendem? 8 de nov. 2017. Disponível em: < https://blog-br.softwareone.com/machine-learningcomo-as-maquinas-aprendem>. Acesso em: 12 de jun. 2019.

TEIXEIRA, Joao Fernandes. 0 que é inteligência artificial? São Paulo: Editora Brasiliense, 1990.

WHEELER, Michael, "Martin Heidegger", A Enciclopédia Stanford de Filosofia (Edição de Inverno de 2018), Edward N. Zalta (org.), Disponível em: $<$ https://plato.stanford.edu/archives/win2018/entries/heidegger/>. Acesso em: 10 jun. 2019.

WILKINS, Neil. Artificial Intelligence: What You Need to Know About Machine Learning, Robotics, Deep Learning, Recommender Systems, Internet of Things, Neural Networks, Reinforcement Learning, and Our Future. Edição do Kindle, 2019.

Recebido em: 27-7-2021

Aprovado em: 15-12-2021 


\section{Renata Albuquerque Lima}

Pós-Doutora em Direito pela Universidade Federal de Santa Catarina. Doutora em Direito Constitucional pela Universidade de Fortaleza - UNIFOR. Graduação em Direito pela Universidade Federal do Ceará (2001), graduação em Administração pela Universidade Estadual do Ceará (2001) e mestrado em Direito (Direito e Desenvolvimento) pela Universidade Federal do Ceará (2003). Atualmente é Professora do Mestrado em Direito e da Graduação em Direito da UNICHRISTUS. É Professora Adjunta do Curso de Direito da Universidade Estadual Vale do Acaraú - UVA, ministrando as disciplinas de Direito Empresarial (Falência), Hermenêutica Jurídica e Introdução à Ciência Política. É coordenadora do Curso de Direito da Faculdade Luciano Feijão - FLF. Membro da Comissão de Ensino Jurídico da OAB-CE.Tem experiência na área de Direito, com ênfase em Direito Empresarial, Direito Constitucional e Hermenêutica Jurídica, atuando principalmente nos seguintes temas: Direito Falimentar, Direito Recuperacional, Direitos Fundamentais e Hermenêutica Constitucional. É líder do Grupo de Pesquisa: Direito, Regulação e Desenvolvimento. Faz parte como pesquisadora do Grupo de Pesquisa: Relações Econômicas, Políticas e Jurídicas na América Latina - REPJAL.

E-mail: realbuquerque@yahoo.com

\section{Marina Nogueira de Almeida}

Mestre em Direito pelo Centro Universitário Christus (Unichristus). Especialista em Direto Material e Processual do Trabalho pela Universidade do Vale do Acaraú (UVA). Graduada em Direito pela Universidade de Fortaleza (UNIFOR). Membro do Grupo de Pesquisa "Desenvolvimento Socioeconômico e a Realização dos Direitos Fundamentais nas Relações Privadas" - IPADE. Servidora Pública Federal do Tribunal Regional do Trabalho.

E-mail: marina.nogueira.alm@gmail.com

Centro Universitário - UNICHRISTUS

Av. Dom Luís, 911 - Meireles, Fortaleza - CE, 60160-230 